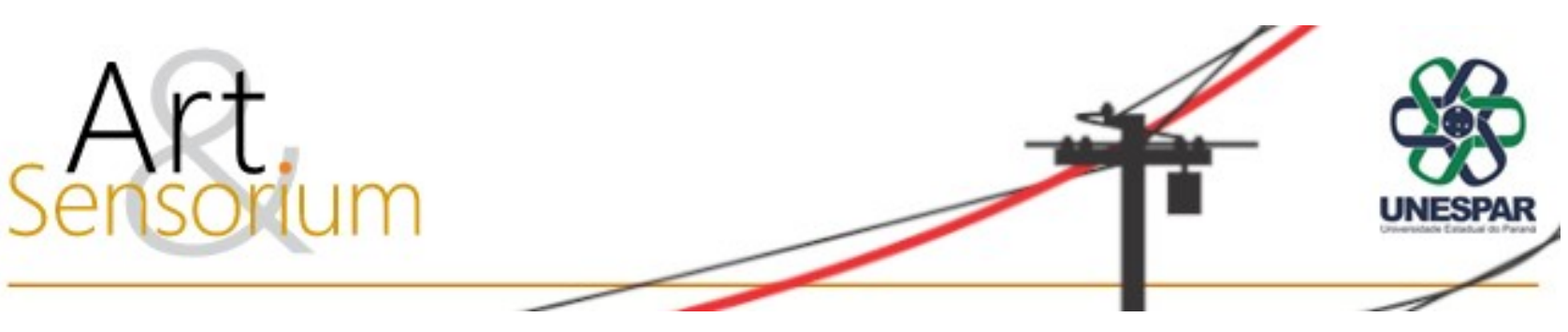

\title{
A PARTICIPAÇÃO ESTUDANTIL NAS AÇÕES ARTÍSTICO-PEDAGÓGICAS DO CAMPO REMOTO: UMA REFLEXÃO BASEADA NAS PRÁTICAS DO PREVIOUSLY E DA NEWSLETTER
}

DOI: https://doi.org/10.33871/23580437.2021.8.2.032-049

\author{
Debora Maria Santiago ${ }^{1}$ \\ Isadora Buzo Mattiolli ${ }^{2}$ \\ Dariane Martiól de Souza $a^{3}$ \\ Douglas Emanuel Mendes Gonçalo de Sousa ${ }^{4}$ \\ Hell Crocetti Pereira ${ }^{5}$ \\ Maira Pires de Castro ${ }^{6}$
}

RESUMO: Este artigo propõe uma reflexão sobre as atividades Previously e Newsletter como propostas que tiveram um expressivo envolvimento estudantil no conjunto de ações artísticopedagógicas do Campo Remoto. O Campo Remoto foi o projeto de ensino emergencial remoto dos cursos de Bacharelado em Artes Visuais da Escola de Música e Belas Artes do Paraná da Universidade Estadual do Paraná, e promoveu atividades síncronas e assíncronas em ambiente virtual no ano de 2020, em decorrência da pandemia de Covid-19. O presente texto é construído

\footnotetext{
${ }^{1}$ Artista e professora adjunta no Bacharelado em Artes Visuais do Centro de Artes da UNESPAR, Campus Curitiba IEMBAP. Doutora em Artes Visuais pelo PPGAV-UDESC na Linha de Pesquisa Processos Artísticos Contemporâneos. Curitiba - PR, Brasil http://lattes.cnpq.br/7041602013934981 https://orcid.org/0000-0001-6720-3097 debora.santiago@unespar.edu.br

${ }^{2}$ Professora no Bacharelado em Artes Visuais do Centro de Artes da UNESPAR, Campus Curitiba I - EMBAP e professora na Pós-Graduação de História e Curadoria na Escola de Belas Artes da PUC-PR. Mestre em História, Teoria e Crítica de Arte pelo PPGAV - UFRGS na Linha de Pesquisa História, Teoria e Crítica de Arte. Curitiba - PR, Brasil http://lattes.cnpq.br/6022375313021139 https://orcid.org/0000-0002-5663-2600 isadora.mattiolli@ies.unespar.edu.br

${ }^{3}$ Artista visual, licenciada em Filosofia e bacharela em Pintura pela UNESPAR, Campus Curitiba I - EMBAP. Mestranda em artes visuais no PPGAV-UDESC na linha de pesquisa: Processos Artísticos Contemporâneos. Coronel Vivida - PR, Brasil http://lattes.cnpq.br/1561828254602992 https:/orcid.org/0000-0002-7526-337X dari.ms@hotmail.com

${ }^{4}$ Artista plástico e estudante do Bacharelado em Superior de Gravura da UNESPAR, Campus Curitiba I - EMBAP. Curitiba - PR, Brasil douglas22@outlook.com

${ }^{5}$ Artista visual e da performance, luthier e estudante do curso de Bacharelado em Artes Visuais da UNESPAR, Campus Curitiba I-EMBAP. Curitiba-PR, Brasil diskhell666@gmail.com

${ }^{6}$ Artista, ilustradora e estudante do curso de Bacharelado em Artes Visuais da UNESPAR, Campus Curitiba I EMBAP. Possui uma produção artística autoral, assinando seus trabalhos com o nome Martemis. Curitiba - PR, Brasil http://lattes.cnpq.br/1380182120862956 https://orcid.org/0000-0001-5379-5060 martemismaira@gmail.com
} 
pelos relatos de professores/as e alunos/as/es que contribuíram com o Previously e a Newsletter evidenciando o caráter pedagógico e formativo dessas experiências. O Previously foi uma proposta de apresentação oral dos temas apresentados nos encontros síncronos, preparados pelos/as alunos/as/es para a Temporada HH do Campo Remoto, dedicada ao estudo da História da Arte por um viés decolonial. A Newsletter do Campo Remoto foi uma atividade assíncrona que consistiu num boletim informativo enviado semanalmente contendo um resumo das atividades do Campo Remoto, que teve como objetivo documentar e divulgar o projeto, além de propor um espaço para a circulação da produção artística discente. Essas duas propostas foram consideradas por uma perspectiva de análise que visa evidenciar a participação colaborativa e transversal entre professores/as e alunos/as/es na construção de ensino-aprendizagem no campo das Artes Visuais.

Palavras-chave: Campo Remoto; Ensino Remoto Emergencial; Previously; Newsletter.

\title{
STUDENT PARTICIPATION IN THE ARTISTIC-PEDAGOGICAL ACTIONS OF CAMPO REMOTO: A REFLECTION BASED ON THE PRACTICES OF PREVIOUSLY AND THE NEWSLETTTER
}

\begin{abstract}
This article proposes a reflection on Previously and Newsletter activities as proposals that had an expressive student involvement in the set of artistic-pedagogical actions in Campo Remoto. Campo Remoto (Remote Field) was the remote emergency teaching projects of the Bachelor of Visual Arts courses at the Escola de Belas Artes do Paraná, Universidade Estadual do Paraná, and promoted synchronous and asynchronous activities in a virtual environment in 2020, as a result of the pandemic of Covid-19. This text is built on the reports of teachers and students who contributed to Previously and the Newsletter, highlighting the pedagogical and formative character of these experiences. Previously was an oral presentation proposal of the themes presented in the synchronous meetings, prepared by students for the study of the History of Art from a decolonial perspective. The Campo Remoto Newsletter was an asynchronous activity that consisted of a weekly newsletter containing a summary of Campo Remoto's activities, which aimed to document and publicize the project, in addition to proposing a space for the circulations of student's artistic production. These two proposals were considered from an analytical perspective that aims to highlight the collaborative and transversal participation between teachers and students in the construction of teaching learning in the field of Visual Arts.
\end{abstract}

Keywords: Remote Field; Remote Emergency Teaching; Previously; Newsletter

\section{PARTICIPACIÓN ESTUDIANTIL EN LAS ACCIONES ARTÍSTICO-PEDAGÓGICAS DE CAMPO REMOTO: UNA REFLEXIÓN A PARTIR DE LAS PRÁCTICAS DE PREVIOUSLY Y LA NEWSLETTER}

Este artículo propone una reflexión sobre las actividades de Previously y Newsletter como propuestas que tuvieron una implicación expresiva de los estudiantes en el conjunto de acciones artístico-pedagógicas en Campo Remoto. Campo Remoto fue el proyecto pedagógico de emergencia remota de los cursos de Licenciatura en Artes Visuales de la Escola de Música e Belas Artes de Paraná, Universidade Estadual do Paraná, y promovió actividades sincrónicas y asincrónicas en un entorno virtual en 2020, a raíz de la pandemia de Covid-19. Este texto se construye a partir de los informes de profesores y alumnos que contribuyeron a Previously y al Newsletter, destacando el carácter pedagógico y formativo de estas experiencias. Previamente se realizó una propuesta de presentación oral de los temas presentados en los encuentros sincrónicos, elaborada por los alumnos para el Ciclo Campo Remoto HH, dedicado al estudio de la Historia del Arte desde una perspectiva decolonial. El Newsletter Campo Remoto fue una actividad asincrónica 
que consistió en un boletín semanal que contenía un resumen de las actividades de Campo Remoto, que tenía como objetivo documentar y dar a conocer el proyecto, además de proponer un espacio para la circulación de la producción artística de los estudiantes. Estas dos propuestas fueron consideradas desde una perspectiva analítica que tiene como objetivo resaltar la participación colaborativa y transversal entre docentes y estudiantes en la construcción de la enseñanzaaprendizaje en el campo de las Artes Visuales.

Palabras clave: Campo Remoto; Enseñanza remota de emergencia; Previously; Newsletter.

A proposta do corpo docente do Curso Bacharelado em Arte Visuais do Centro de Artes da UNESPAR, Campus Curitiba I - EMBAP, intitulada Campo Remoto, para o ano letivo de 2020 foi desafiadora, tanto para o próprio corpo docente como para o discente. A pandemia Covid-19, ou sindemia como muitos/as autores/as têm afirmado ${ }^{7}$, em que além do vírus causador da doença temse uma série de síndromes crônicas não transmissíveis interagindo com a infecção pelo coronavírus e atingido com mais intensidade países caracterizados por contextos sociais e ambientes com profunda desigualdade social, tem apresentado desafios dos mais diversos ao campo da educação. No Brasil, um país marcado por desigualdades e exclusões sociais, o ensino em uma universidade pública nesse contexto tem nos provocado não somente em relação aos formatos possíveis de ensino remoto emergencial, mas também ao acesso dos/das/des estudantes a esses formatos e a continuidade de seus estudos. A preocupação com o acesso ao ensino e a permanência estudantil tornou-se ainda maior, exigindo mais esforços dos programas de inclusão digital, de bolsas e da atuação dos núcleos de ação do Centro de Educação em Direitos Humanos da UNESPAR.

O Campo Remoto se estruturou por meio de um conjunto de ações orgânicas e sujeitas a transformações e adaptações ao longo da sua própria realização, que aconteceram por meio de encontros virtuais síncronos e também por atividades assíncronas. As ações síncronas foram chamadas de Temporadas, guiadas por um tema em comum, que se desdobravam em alguns Episódios. Por ordem de realização, foram: EEPP (Escultura Encontrada Pintura Pronta), AVC (Artes Visuais e Conservação), HH (História Hegemônica, Herética, Hedionda, Heterogênea) e JPEG (Jogos, Poéticas, Estratégias e Gamificação).

A retomada dos assuntos anteriores entre uma aula e outra - ou melhor, entre os Episódios - foi uma constante no Campo Remoto. Já na primeira temporada, EEPP / Escultura Encontrada Pintura Pronta, professores/as que acompanhavam as apresentações de seus colegas junto com os/as/es estudantes, traziam para o início dos encontros uma espécie de memória do Episódio anterior, ao mesmo tempo que criavam outras camadas a partir de seus repertórios. Com as contribuições e questionamentos dos/das/des professores/as essas reflexões iam adensando o tema proposto. Tais apresentações foram chamadas de Previously.

Antes de iniciarmos a terceira Temporada, em uma das nossas reuniões semanais de colegiado, começamos a pensar na participação estudantil. Nós, professores/as, vínhamos nos questionando sobre que tipo de trocas estávamos proporcionando durante os encontros, as discussões ocorriam,

\footnotetext{
${ }^{7}$ Textos em revistas científicas e jornais independentes têm trazido essa abordagem desde meados de 2020. Ver texto "Pandemia e pobreza: a sindemia exposta da crueldade humana" publicado no Le Monde Diplomatique Brasil em 23/11/2020, disponível em https://diplomatique.org.br/pandemia-e-pobreza-a-sindemia-exposta-da-crueldade-humana/. Acesso em 27/08/2021.
} 
mas com pouca interação. Sugerimos então que os/as/es estudantes realizassem o Previously a partir da terceira temporada.

Outras atividades síncronas semanais foram os encontros do Campis Remotis (noite de microfone aberto), o Ateliê Remoto (visitas virtuais a ateliês de artistas mediada pelos professores) e as disciplinas optativas Site-especificidade como modalidade na Arte Contemporânea, oferecida pela Professora Deborah Bruel e Videoperformance em tempos de encarceramento, oferecida pelo Professor Fábio Noronha.

As atividades assíncronas consistiram em vídeo-aulas e material de apoio pedagógico compartilhado no Google Classroom do Campo Remoto, o evento de extensão Encontros com Arte (entrevistas ao vivo com agentes do campo artístico), coordenado pela Professora Lilian Gassen e a Newsletter do Campo Remoto (boletim semanal de documentação e divulgação das ações do Campo Remoto e da produção artística discente), editado pela Professora Isadora Mattiolli. Foram todas atividades remotas emergenciais que tiveram o objetivo de restabelecer o contato entre alunos/as/es e professores/as, proporcionando o diálogo bem como a produção artística e teórica.

Algumas dessas ações contaram com o envolvimento dos/das/des alunos/as/es, convidados a participarem de diferentes maneiras: apresentando o Previously, pesquisas de Iniciação Científica, trabalhos artísticos, entre outros assuntos teóricos, históricos ou práticos que fazem parte de seus estudos. Tais atuações ocorreram em alguns projetos específicos: no já mencionado Previously, no episódio História Heterogênea, no Campis Remotis, na Newsletter e em determinados episódios a convite dos professores/as.

Entre os convites específicos, o terceiro episódio do JPEG contou com a participação da Professora Keila Kern e da discente Marina Raimundini, que num jogo de interpretação de papéis encenaram uma entrevista do artista Adrián Villar Rojas (interpretado pela Marina), concedida ao pesquisador Hans Ulrich Obrist (interpretado pela Keila).

E ainda, os dois últimos episódios da Temporada de encontros síncronos $\mathrm{HH}$ foram dedicados para a divulgação e debate de pesquisas realizadas pelos estudantes. O ciclo História Heterogênea foi pensado para refletir a diversidade de abordagens, metodologias e temas da história da arte. Os estudos apresentados integram o Programa Institucional de Iniciação Científica da UNESPAR, pesquisadores/as do Programa de Pós-Graduação em Artes da UNESPAR e também do Programa de Pós-Graduação em Museologia e Patrimônio da UNIRIO ${ }^{8}$.

No caso da Newsletter do Campo Remoto, os/as estudantes eram convidados/as/es a colaborarem com a produção de textos e relatos sobre as suas experiências e a se envolveram principalmente compartilhando os seus trabalhos artísticos desenvolvidos a partir das Temporadas, bem como divulgando os resultados parciais de suas Cartografias, atividade sugerida como avaliação de ensino-aprendizagem do Campo Remoto. Essa foi uma atividade assíncrona que desde a sua concepção foi pensada para incluir os alunos/as/es na documentação e criação de sentido do Campo Remoto.

A Newsletter também contou com a contribuição institucional de Hell Crocetti, bolsista do projeto de monitoria acadêmica Monitoria no Campo Remoto, auxiliando na documentação das ações e na criação de arquivo das atividades, sobre as quais escrevia textos para serem publicados nos boletins informativos (tradução de Newsletter para o português). Um dos objetivos da monitoria foi o desenvolvimento de reflexão teórica sobre o Campo Remoto. A aluna auxiliou na documentação

\footnotetext{
${ }^{8}$ Informação contida na Newsletter \#13 do Campo Remoto.
} 
das ações e na criação de arquivo das atividades, escrevendo textos sobre as atividades ocorridas para serem publicados na Newsletter, enviada todas às segundas-feiras.

No total, foram dezenove boletins informativos enviados semanalmente às segundas-feiras. $\mathrm{O}$ projeto editorial dos boletins consistiu numa descrição textual das ações do Campo Remoto, geralmente acompanhadas de imagens. A estrutura foi quase sempre a mesma: primeiro, um texto explicativo sobre a Newsletter e o Campo Remoto e, em seguida, um resumo dos episódios da semana, um relato sobre o Ateliê Remoto, algum acontecimento do Campis Remotis, o compartilhamento de Cartografia em processo de algum/a estudante, a agenda da próxima semana e, no fechamento, o registro do trabalho de algum/a artista que fosse relacionado ao tema "casa". O que mudava nessa ordenação era a inclusão de uma resenha sobre as atividades assíncronas, que tinham assiduidade e características distintas. A maioria dos textos foi escrita por Hell Crocetti e pela professora Isadora que também foi responsável pela diagramação e o envio dos boletins, hospedados no site de e-mail marketing Tinyletter ${ }^{9}$.

O projeto editorial da Newsletter do Campo Remoto possibilitou uma reflexão sobre a proposta de ações artístico-educativas elaboradas pelo colegiado do Bacharelado em Artes Visuais, que surgiu como uma necessidade de adaptação às condições sanitárias atuais, mas que reflete o caráter de experimentação e ruptura próprios ao campo artístico e destaca um dos papéis sociais da produção artística que é o de processar, refletir e agir sobre a realidade que vivemos.

Nessa perspectiva, os boletins informativos criaram a memória desse conjunto de práticas e constituem um documento histórico e pedagógico que as descreve. No exercício de descrição, também é possível notar a construção de sentido sobre o Campo Remoto no fazer da Newsletter. Enquanto nos textos era possível acompanhar os relatos das experiências daquela semana, pode ser observado também como as atividades anteriores foram interpretadas e assimiladas nos compartilhamentos das Cartografias. Pelo conteúdo da Newsletter era possível perceber como os assuntos estavam sempre retornando e em relação contínua ao passar das semanas.

Por outro lado, os boletins se tornaram um material didático para os/as discentes no desenvolvimento de seus trabalhos de avaliação final de todas as disciplinas contempladas pelo Campo Remoto, avaliação que consistiu na realização de uma Cartografia. Isso se evidenciou através das bancas de defesa das Cartografias, onde foi possível perceber que os estudantes recorreram a Newsletter como material de apoio para os seus processos cartográficos, uma vez que as apresentações finais ocorreram meses depois das aulas síncronas, sendo necessário a consulta desses arquivos.

As propostas desenvolvidas coletivamente entre docentes e discentes foram marcadas pela interdisciplinaridade dos saberes compartilhados e oferecidas a todos/as/es. O presente texto se propõe a trazer relatos e reflexões sobre a participação estudantil em algumas ações do Campo Remoto. Para tanto, foi estruturado em quatro partes trazendo a experiência dos/das/des estudantes que partilharam da proposta.

De início, a estudante Hell Croccetti Pereira fala de sua participação como aluna e bolsista do projeto Monitoria no Campo Remoto. A segunda parte, Previously on HH, traz as reflexões de Maira Pires de Castro sobre a temporada $\mathrm{HH}$, sua participação em um dos episódios e sua pesquisa no Programa de Iniciação Científica. Em seguida, Douglas Gonçalo, formando do curso de Gravura, fala da sua contribuição no Previously relacionada ao episódio História Herege da temporada HH. E

\footnotetext{
${ }^{9}$ Esses boletins estão disponíveis em https://tinyletter.com/campusremotus/archive
} 
na quarta parte, também sobre o HH, Dariane Martiól, discute suas ideias para o episódio História Hedionda.

Algumas apresentações de professores/as foram citadas nesses relatos, porém correspondem apenas a recortes das falas para contextualização do assunto. Também optamos por manter informações sobre o Campo Remoto, mesmo que tenham sido abordadas acima, pois trazem diferentes olhares sobre a intenção do mesmo.

\section{Diversos caminhos no Campo Remoto por Hell Crocetti Pereira}

Como aluna da primeira turma do recém criado Curso Superior de Bacharelado em Artes Visuais, iniciei meu segundo ano na EMBAP ansiosa pelos novos conhecimentos que 2020 traria. Mal sabia eu que participaria presencialmente apenas de duas aulas, pois logo nas primeiras semanas do semestre a pandemia que assolou e ainda assola o mundo chegaria ao Brasil e mudaria a forma de existir em sociedade e, para além de suas consequências mais severas, também mudaria a forma de ensino no país. A quarentena, que a princípio imaginávamos que duraria duas semanas, se estendeu por meses e o pensamento sobre ensino remoto foi se aprofundando com pesquisas de acesso aos alunos/as/es. Particularmente, ao tentar participar das aulas à distância, encontrei muitas dificuldades além daquelas já existentes na conexão virtual; tudo parecia mais difícil, pesado e as aulas e debates com colegas que antes serviam de estímulo para pesquisas e trabalhos extracurriculares agora eram cansativas e a capacidade de reter conteúdos parecia ter desaparecido do cérebro. Em conversas com colegas, descobri que muitos se sentiam da mesma forma. Alimentados por uma esperança infundada da volta às aulas presenciais, muitos demoraram a iniciar a participação nos conteúdos virtuais e, ao entrarem, já estavam atrasados/as/es, frustrados/as/es com tecnologias novas e a dificuldade de se manter com saúde mental para estudar. Em meio ao caos global, muitos desistiram de participar das aulas em geral e eu, eventualmente, me sentindo da mesma forma, também desisti.

Embora não estivesse muito animada, quando os professores nos convidaram para participar do Campo Remoto, eu decidi acompanhar, pois os estudos de artes pelos quais sou apaixonada faziam muita falta ao meu cérebro deprimido e desestimulado pelo confinamento. Logo no primeiro episódio do EEPP, me apaixonei pela proposta e passei a esperar ansiosamente toda semana pelos episódios, a fazer anotações com ideias de novos projetos e pesquisas, tanto para a Cartografia, quanto por um interesse renascido em aprender e criar e a participar com perguntas aos professores geradas pelas novas conexões mentais criadas. Conforme as semanas foram passando e a participação dos/das/es alunos/as/es se tornou mais presente e intensa, me senti também à vontade para colaborar.

Minha participação no Campo Remoto aconteceu em três situações: como aluna na preparação do Previously de um episódio da temporada JPEG, como convidada para uma fala sobre jogos de transformismo também para o JPEG e como colaboradora do projeto Newsletter do Campo Remoto, pelo programa de monitoria acadêmica com orientação da professora Isadora Buzo Mattiolli.

Para o Previously (recapitulação do episódio anterior com adição de novas ideias e referências) do segundo episódio do JPEG (Jogos, Poéticas, Estratégias e Gamificação) usei como inspiração o trabalho anterior dos/as/es alunos/as/es em outros dias e as aulas dos professores Fabrício Vaz Nunes e Everaldo Skrock. O professor Fabrício Nunes apresentou o conceito da nova temporada que visava relacionar diferentes conceitos e teorias de jogos com a arte. $\mathrm{O}$ professor trouxe como referências a obra "A loteria da Babilônia" (1941) do escritor argentino Jorge Luís Borges (18991986), traçando diversos paralelos entre a arte moderna e o jogo, além disso apresentou e discutiu 
obras de diversos períodos e regiões nas quais os jogos são ambientados. Como forma de expandir o assunto, apresentei obras do artista Maurits Cornelis Escher (1898-1972) com representações de jogos e que também utilizam de ilusões ópticas para "jogar" com a percepção da realidade de seus observadores.

O professor Everaldo Skrock explicou a tipologia dos Jogos segundo Roger Caillois (1913- 1978), divididas em quatro categorias: Agon, Alea, Mimicry e Ilinx, suas formas de corrupções e institucionalizações e abordando o círculo mágico que é paralelo à zona autônoma temporal estabelecida na arte. Para complementar e relacionar com este conceito, apresentei os trabalhos de Ricardo Nolasco, artista contemporâneo residente na Selvática Ações Artísticas em Curitiba, que dentre outros temas trabalha em sua poética performática cabaretera e instalações o uso do jogo de Tarot. Para terminar minha participação, trouxe a exposição Dismaland (Somerset, Inglaterra, 2015) organizada pelo artista anônimo Banksy que, com a participação de mais 58 artistas, fazia uma paródia aos famosos parques de diversões de Walt Disney (1901-1966), mesclando a atmosfera lúdica destes locais com obras contemporâneas de teor ácido e político.

Depois, alguns/as alunos/as/es foram convidados pelo professor Fabrício Nunes a apresentarem uma fala sobre assuntos de suas pesquisas individuais que se relacionavam com o tema da temporada JPEG. Sendo artista drag queen e drag king há quatro anos, integrando diversos grupos da cena curitibana, amante e pesquisadora da área, fui convidada a dar uma fala sobre os jogos de transformismo presentes no universo da arte drag. Em minha fala, abordei os diversos estilos e possibilidades de expressão drag, trouxe o contexto histórico dessa forma de expressão no mundo e também no Brasil, respondi algumas dúvidas comuns a respeito de drags e outras identidades não artísticas da sigla LGBTQIAP+, apresentei diversos artistas da cena internacional, nacional e curitibana de variados períodos e iniciei uma discussão sobre performatividade de papéis de gênero na vida cotidiana e de forma artística.

Por fim, realizado durante quatro meses do Campo Remoto, o projeto de monitoria acadêmica do qual participei me proporcionou realizar diversas atividades relacionadas às aulas, como preparações para os encontros virtuais com os artistas convidados em seus ateliês, que ocorriam às sextas-feiras, a divulgação dos episódios com os demais alunos e, de forma mais extensa, na coparticipação da escrita da Newsletter do Campo Remoto. O projeto da Newsletter teve como intuito a recapitulação semanal para todos os interessados em acompanhar as atividades que ocorriam no Campo Remoto, trazendo relatos sobre os conteúdos abordados, dos Ateliês Remotos e de algumas das Cartografias apresentadas semanalmente pelos estudantes. Adicionalmente, ao seu final, a Newsletter sempre trazia uma obra relacionada ao Campo Remoto. Ela também representa um registro para futuras consultas, condensando o que aconteceu durante este período tão excepcional e como foram abordadas as diferentes formas de estudos que uniu professores de diferentes áreas, gerando conexões e palestras que provavelmente não ocorreriam desta forma fossem outras as circunstâncias, o que enriqueceu muito o repertório dos/as/es alunos/as/es participantes.

Participar deste projeto de monitoria me proporcionou um contato mais íntimo com as falas apresentadas, sendo que uma escuta mais ativa se fez necessária, bem como anotações mais completas e a posterior revisão semanal e síntese dos conteúdos para traduzi-los em parágrafos da Newsletter, o que me levou a fixar melhor os conteúdos passados. Sempre o fazia com o intuito de que os/as leitores/as pudessem ter a mesma sensação, mesmo não podendo estar presente nas aulas síncronas. Que pudessem aprender e, eventualmente, pesquisar mais a respeito dos temas tratados em cada episódio do Campo Remoto, sendo estes leitores não participantes das aulas ou, ainda, leitores futuros. As reuniões periódicas com a professora orientadora também foram importantes para programações e exercícios de revisões dos textos, aos quais sempre me foi dada liberdade de 
escrever como encontrasse mais adequado dentro da proposta, o que me proporcionou um exercício de escrita em uma área na qual não estava habituada.

Em uma época em que nenhuma solução parecia fácil para o ensino virtual, o Campo Remoto proporcionou aos estudantes uma experiência única de compartilhamento e absorção de conhecimentos de uma maneira empática às necessidades que aparecem em um momento de exceção para os/as/es professores/as e alunos/as/es participantes. As possibilidades de participação para os/as/es estudantes que desejassem estar mais imersos/as nas propostas do Campo Remoto gerou o exercício de habilidades novas em um ambiente de amplo suporte e incentivo.

\section{Previously on HH por Maira Pires de Castro}

Hegemonia significa a predominância de algo sobre outra coisa. A supremacia e influência que uma ideia pode ter sobre um determinado grupo de pessoas, afetando historicamente populações e interferindo direta ou indiretamente em gerações. Sendo assim, dentro do Campo Remoto - espaço remoto de ensino e atividade emergencial proposto a partir do segundo semestre de 2020 pelo Colegiado de Bacharelado em Artes Visuais da Escola de Música e Belas Artes do Paraná (Unespar, Campus Curitiba I) -, nos dias 29 e 30 de setembro de 2020, professores/as e estudantes se reuniram virtualmente para debater um tema central, as Histórias Hegemônicas, no qual pudemos observar a História da humanidade a partir de uma perspectiva marcada por lutas de poder e imposições e a História da Arte, sendo fruto de tais conflitos, constituindo-se como uma narrativa de exclusões.

Dentre tantos/as/es discentes que o ambiente on-line comportou, muitas vezes passando de 100 pessoas reunidas no Google Meet, estabeleceu-se como dinâmica para retomada dos conteúdos trabalhados nas aulas o chamado Previously, satirizando as séries estadunidenses que transmitem antes de cada capítulo o que houve de mais relevante no episódio anterior, podendo o/a/e professor/a encarregado/a adicionar suas próprias referências e conexões que teve ao testemunhar a aula passada. Dentro das Temporadas do Campo Remoto, os encontros do HH estiveram mais conectados com conteúdos acerca da História da Arte e seus contextos hegemônicos, hereges, hediondos e, por fim, heterogênicos - comportando nesse último a apresentação das pesquisas de iniciação científica de estudantes inscritos. Outra novidade é que agora, no $\mathrm{HH}$, seriam os/as alunos/as encarregados/as/es dos Previously de cada aula, necessitando apenas de uma prévia manifestação de interesse. Nesse sentido, encarreguei-me de retomar os conteúdos do encontro Histórias Hegemônicas, que contou com as falas da professora Katiucya Perigo e dos professores Luiz Carlos Sereza e Fabricio Vaz Nunes.

Utilizando da liberdade criativa que foi dada para abordagem dos assuntos, primeiramente inverti a ordem das apresentações, iniciando pelo professor Fabricio, que tratou sobre a colonização da Mesoamérica e a exigência religiosa sobre a cultura Mexica, principalmente. Apesar da grave e violenta imposição hispânica e religiosa, o professor expôs em aula a complexidade que este período comporta, uma vez que nem os mexicas eram povos pacíficos e mitificados, comportandose como vítimas passivas das atrocidades espanholas; nem os próprios europeus conseguiram efetuar uma investida rápida e logo alcançando um sucesso colonial e ideológico sobre a terra prometida. A colonização espanhola - apesar de brutal e violenta - compreende também um período de miscigenação (ainda que forçada), choque cultural e, acima disso, o fracasso hegemônico das ideias católicas e europeias sobre uma cultura descrita como primitiva. Por essa razão, minha fala contemplou um pouco dos mitos e cultura dos Mexicas, dando espaço para a 
memória dos povos originários que deve ser estudada e repassada como um patrimônio cultural latino-americano.

Em seguida, falei sobre os temas levantados pelo professor Sereza, que abordou brevemente a Revolução Russa de fevereiro de 1917 e a pós-Revolução de Outubro de 1917, no qual ocorreu um fortalecimento do pensamento construtivista pelo grupo Frente de Esquerda das Artes (LEF). Nesse contexto, a arte, até então refém de padrões estéticos de pureza e representação, estava sendo reformulada pela vanguarda russa a uma gama de produções e debates que visavam reformular paradigmas tradicionais e lhe adicionar uma nova função social, dando-lhe uma aplicabilidade no cotidiano de uma população predominantemente camponesa e analfabeta e contribuindo para uma cisão entre a arte e a vida. Por esse motivo e pensando na circulação massiva de materiais engajados e artísticos que visam fortalecer ideais sobre igualdade e coletividade, logo relacionei a apresentação à minha pesquisa de iniciação científica "Oesterheld e Breccia: $\mathrm{O}$ gênero fantástico nos quadrinhos argentinos”, tratando especificamente de Héctor Germán Oesterheld (1919-1977), escritor argentino de historietas que sempre apreciou a circulação massiva de suas histórias, pois acreditava que materiais de boa qualidade literária e estética devem sim pertencer às massas, não sendo apenas restritas às elites sociais.

Finalizei minha apresentação expondo o conteúdo trabalhado pela professora Katiucya, que nos mostrou um pouco do Manifesto Futurista (1909) e sua inclinação explicitamente fascista, exaltando a violência, as guerras, o militarismo, os avanços tecnológicos e o repúdio ao passado, à memória e às mulheres. Além disso, a professora reforçou em sua fala como a História da Arte é fundamentada por relações de poder, demonstrando a artificialidade da disciplina que ainda se constrói sob uma fundamentação eurocêntrica. Contudo, a professora Katiucya, assim como outros/as/es professores/as, buscam decolonizar esse conhecimento, deslocando-o para uma perspectiva latino-americana e nos devolvendo algo que nos é roubado todos os dias: a nossa memória e história brasileira. Por isso, ela optou em debater sobre o Futurismo a partir da vinda do artista italiano Filippo Tommaso Marinetti ao Brasil - em 1936 - e a repercussão hegemônica sentida entre os intelectuais da época, sobretudo Oswald de Andrade e Mário de Andrade.

Esse olhar atento e profundo sobre as aulas do Campo Remoto representou uma experiência investigativa, compreendendo a pesquisa artística como um estudo engajado sob a história, cultura e sociedade e consequentemente, atenta aos debates políticos, econômicos e humanitários, sem desvincular a arte de uma visão crítica sobre a vida. Além disso, devido à hegemonia de certas ideias, infelizmente muitas histórias latino-americanas, feministas, negras, LGBTQIA+ - e/ou outros aspectos que destoam dos valores eurocêntricos imperialistas - foram silenciadas e apagadas pela História da Arte e que, à vista disso, devem ser revisitadas com uma investigação mais engajada de como se entende a história geral, dando-lhes a visibilidade que lhes foi tirada, sem dissociá-las ou reduzi-las apenas aos seus momentos de repressão. Pensando nisso, minha fala encerrou-se com a recomendação do filme Vidas ao Vento (2014, Studio Ghibli), pois mesmo sendo uma obra que aborda a ascensão da Segunda Guerra Mundial e a superprodução imperialista/capitalista ocidental afetando a sociedade japonesa, ainda é um filme que trata temas sensíveis como o suicídio, a ansiedade e a busca de sonhos impossíveis em meio a uma sociedade em colapso, sendo uma das produções mais lindas que já assisti em toda minha vida.

Por fim, o Campo Remoto configurou-se como um espaço de aulas e encontros de professores/as e dezenas de estudantes que, apesar de ter possuído eventuais perdas devido ao ensino on-line que era previsto a ser dado presencialmente, possibilitou trocas e experiências criativas que muitas vezes não eram imaginadas em seu formato anterior à pandemia. Dentre os encontros, as aulas ministradas pelos professores do $\mathrm{HH}$ mostrou-se um momento particularmente interativo, no qual os estudantes eram convidados a participar mais ativamente através de propostas como o previously 
e apresentando seus projetos de pesquisa no Histórias Heterogêneas, ocorrido nos dias 27 e 28 de outubro de 2020, no qual participei expondo os resultados parciais da minha pesquisa de iniciação científica (na época, em andamento).

"Oesterheld e Breccia: O gênero fantástico nos quadrinhos argentinos" representa a minha primeira experiência enquanto pesquisadora, sendo orientada pelo professor Fabricio Vaz Nunes e desenvolvendo-a oficialmente entre os meses de setembro de 2020 e agosto de 2021. Tanto a pesquisa e orientação quanto sua primeira exposição oficial no Histórias Hegemônicas se deu remotamente, sendo uma experiência complementar e lógica ao modelo investigativo adotado pela pesquisa - referindo-me desde a coleta de informações, levantamento bibliográfico, até a evolução teórica. Como parte integrante do projeto "O fantástico em trânsito: intermediações e deslocamentos do insólito latino-americano", minha pesquisa propõe a investigação das historietas argentinas que estão conectadas temática e esteticamente ao gênero fantástico, analisando a transposição intermidiática que ocorre da literatura fantástica para a linguagem híbrida e gráfica das histórias em quadrinhos. Nesse sentido, parto meu estudo aprofundando-me inicialmente nas obras de dois autores: o escritor argentino Héctor Germán Oesterheld (1919-1977) e o artista uruguaioargentino Alberto Breccia (1929-1993); para, em seguida, expandir minha análise a outros quadrinistas argentinos que foram influenciados tanto pela escrita engajada e fantástica de Oesterheld quanto pelos traços insólitos, horrendos e experimentais de Breccia.

Apresentar tais resultados parciais de forma remota foi uma experiência estranhamente reconfortante, pois o formato on-line já era familiar à minha pesquisa. Ao mesmo tempo, o ambiente das Histórias Heterogêneas serviu para demonstrar uma pluralidade de temáticas, contemplando uma parcela das ricas pesquisas desenvolvidas no campo das Artes Visuais e suas múltiplas narrativas acerca do estudo sobre diferentes Histórias da Arte sob olhares críticos, comprometidos e engajados.

\section{Herege Transversal - Previously por Douglas Emanuel Mendes Gonçalo de Sousa}

Em agosto de 2020, o ensino na Escola de Música e Belas Artes (EMBAP - Campus I Curitiba) iniciava em um novo formato subordinado às circunstâncias sociais e político-sanitárias impostas a todos naquele momento e que vigoram até os dias atuais. A pandemia de COVID-19 (Sars-CoV-2) impossibilitou as atividades coletivas presenciais, travou os mais diversos setores da economia, e causou danos irreparáveis, assim fazendo repensar em como poderíamos retomar nossas atividades, entre elas as aulas.

Devido à tal situação, o colegiado do Bacharelado em Artes Visuais propôs como atividade de Ensino Remoto Emergencial o Campo Remoto com o intuito de dar continuidade às aulas do ano letivo de 2020. Em uma proposta inédita e nada usual, professores/as se viram obrigados a repensar o ensino das artes em um âmbito digital, em criar estratégias que atraíssem alunos/as/es e ao mesmo tempo os motivasse, um árduo trabalho de ambas as classes. Nesta nova sala, a cibernética, foi explorado o debate das artes, em seus mais diversos e inexplorados aspectos, de trocadilhos com a história às práticas virtualizadas e até exposições e exploração de Ateliês Remotos. Em cada temporada foi abordado um novo aspecto da história da arte com tamanha expertise e sagacidade que soava como um jogo em que todos/as/es participavam, em que o conteúdo era a moeda de troca dos/as/es jogadores/as.

Ao fim de cada episódio, a partir da terceira Temporada, um/a aluno/a/e era convidado/a/e a apresentar um Previously, retomando questões apresentadas anteriormente. Eu fui extremamente resistente a adentrar no Campo Remoto, inclusive o ignorei por três semanas após seu início, me 
rendi no final de agosto e depois me afeiçoei a maneira que as aulas estavam sendo abordadas, percebi que o foco seria trazer para esta sala virtual o debate artístico já que não teríamos nossas aulas presenciais. Em um destes encontros, me propus a apresentar sobre o episódio História Herege. Uma definição simples e extremamente disseminada durante a Idade Média diz que "herege" é todo aquele contrário a uma doutrina estabelecida pela igreja como dogma, ou indivíduos que sustentam pensamentos e doutrinas contrárias às admitidas.

Pensando a partir desta perspectiva, decidi iniciar o Previously abordando a origem do termo heresia e apresentando indivíduos célebres que marcaram a história por serem considerados/as/es hereges". Joana D'arc, de camponesa a heroína na guerra dos cem anos, e hoje elevada ao cânone de Santa; Martinho Lutero, que desafiava a instituição com a publicação de um livro com suas 95 teses; Sinéad O’Connor, notória cantora e compositora irlandesa que chegou ao topo das paradas nos anos 90 com um hit escrito pelas mãos do Prince e que comprou briga com o Vaticano ao rasgar uma foto do então papa João Paulo II em uma apresentação no programa de maior audiência da televisão americana o Saturday Night Live em 1992; Madonna, a eterna rainha do pop era figura carimbada em embates e provocações também com o Vaticano, seja em suas músicas, videoclipes e performances que sensualizava com santos, adereços religiosos ou em locações das suas gravações audiovisuais que remetiam a igrejas, imortalizadas, ao menos na história da cultura pop; Juan Perón e sua confusa excomunhão em 1955, por ter proibido uma procissão de corpus christi e mandado dois membros do clero para fora do país; Che Guevara e o regime Comunista visto pela igreja como profano. Todos têm em comum o fato de terem sido excomungados pela Igreja Católica em algum momento da história.

Contudo, ao falarmos de heresia na arte abordei a obra de duas grandes artistas brasileiras, mulheres à frente de seu tempo, que poderiam ser consideradas duplamente hereges: apenas por serem mulheres e artistas que provocaram discussões que estão em voga até hoje.

A primeira delas Márcia Pinheiro de Oliveira ou melhor Márcia X, artista que tinha um poderosíssimo trabalho no campo da performance, mas que não se limitava apenas a esta linguagem por ter uma produção que transitava entre os mais diversos campos da arte. No início dos anos 1980, entra na Escola de Artes Visuais do Parque Lage (RJ) e apresenta a sua primeira performance "Cozinhar-te", que aconteceu no $3^{\circ}$ Salão Nacional de Belas Artes junto ao coletivo Cuidado louças.

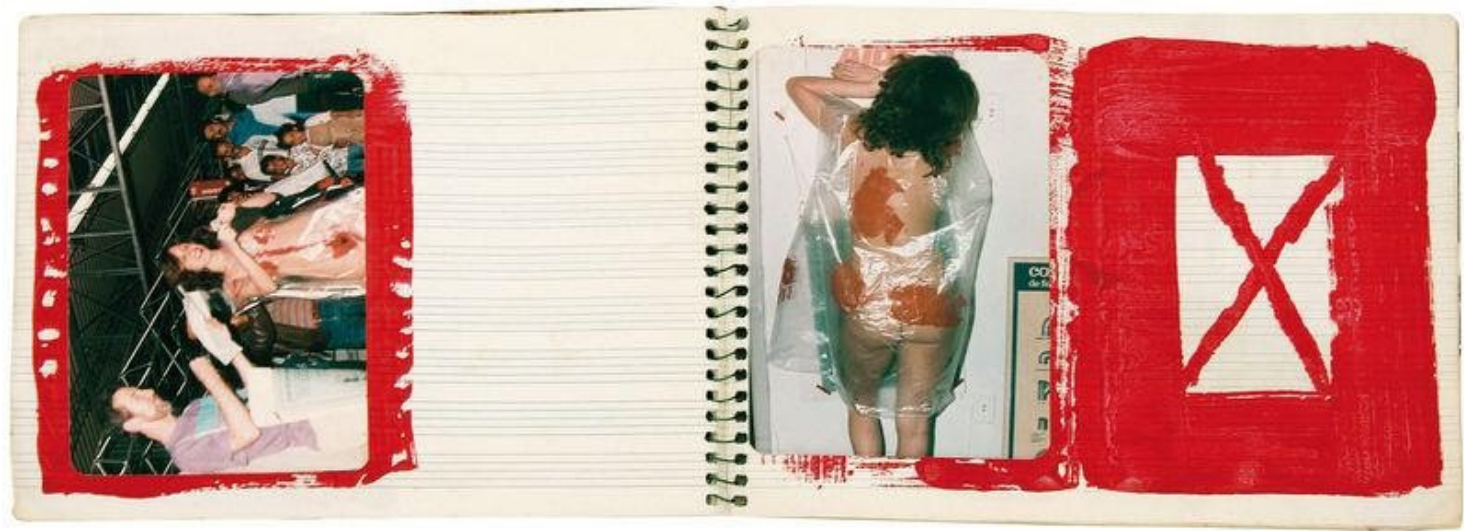

Fig.1. Márcia X., Celofane Motel Suíte/Não roupas (1985). Fonte: https://hammer.ucla.edu/radicalwomen/art/art/celofane-motel-suite-notebook 
Márcia adota o X em seu nome após uma performance conjunta com Alex Hamburguer em 1985, na feira internacional do livro no Rio de Janeiro. Ela estava vestindo uma roupa feita de saco plástico preto e transparente e enquanto lia um poema Alex cortava sua roupa até ela ficar nua. $\mathrm{O}$ problema foi que no dia seguinte a estilista homônima Márcia Pinheiro reagiu a esta performance nas colunas sociais dizendo que ela, a estilista, estava ocupada em vestir as pessoas e não despir. A partir de então Márcia Pinheiro virou Márcia X. Ricardo Bausbaum (2003, p.01) fala sobre o "X" que a acompanha desde 1985 ser mais do que uma incógnita de primeiro grau adornando seu nome. O efeito inevitável parece ser aquele de um mistério que não deseja se resolver.

Além de suas performances, Márcia X produziu nos anos 1990 trabalhos que transformam objetos pornográficos em objetos infantis e vice-versa, assim misturando elementos de posições antagônicas nas convenções sociais e códigos morais. Em sua série Fábrica Fallus, desenvolvida entre 1992 e 2004, ela se apropria de objetos que encontrou em sex shops da região do Saara, zona de comércio famosa no Rio de Janeiro, subvertendo seus significados e remetendo a temas como feminino, infância e religião. Desta forma, ela criou um diálogo direto com público usando objetos cotidianos e encontrados facilmente.

Neste meio tempo Márcia X retomou sua performance em uma poderosa e sutil instalação, que era provocativa e debatia o sagrado e o profano. Desenhando com terços, trabalho de grande impacto e que gerou fúria de parcela da sociedade e igreja, pois a artista, como o próprio título diz, usava terços católicos para criar desenhos de pênis no chão, milhares deles em um ato repetitivo usando uma locação e em grandes proporções e até preencher todo o ambiente.

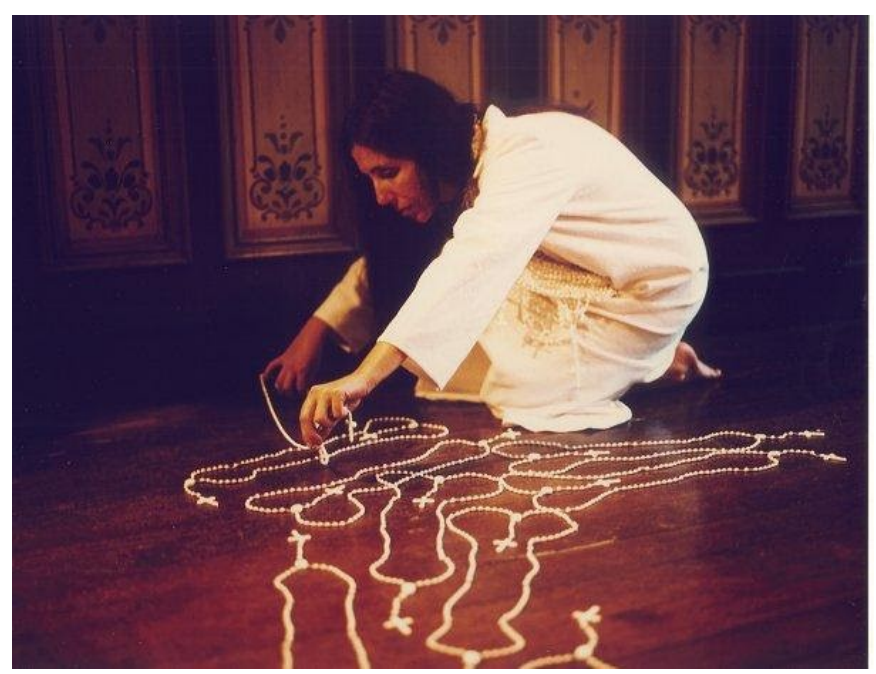

Fig.2. Márcia X., Desenhando com terços (2000). Fonte: http://marciax.art.br/mxObra.asp?sMenu=2\&sObra=26

A outra artista é a surrealista brasileira e aquela que veio dos trópicos: Maria Martins, estudou na Bélgica e morou em Nova York, porém sempre se manteve em diálogo com o Brasil. Uma mulher ímpar e singular na arte brasileira, notoriamente conhecida por suas esculturas imponentes em bronze, Maria Martins trata a sexualidade de maneira explícita e ao mesmo tempo bastante profunda como condição humana. Acho que no século passado, talvez a única que se equipare a escultora brasileira com sua tamanha ferocidade e objetividade ao tratar a sexualidade seja Louise Bourgeois. 


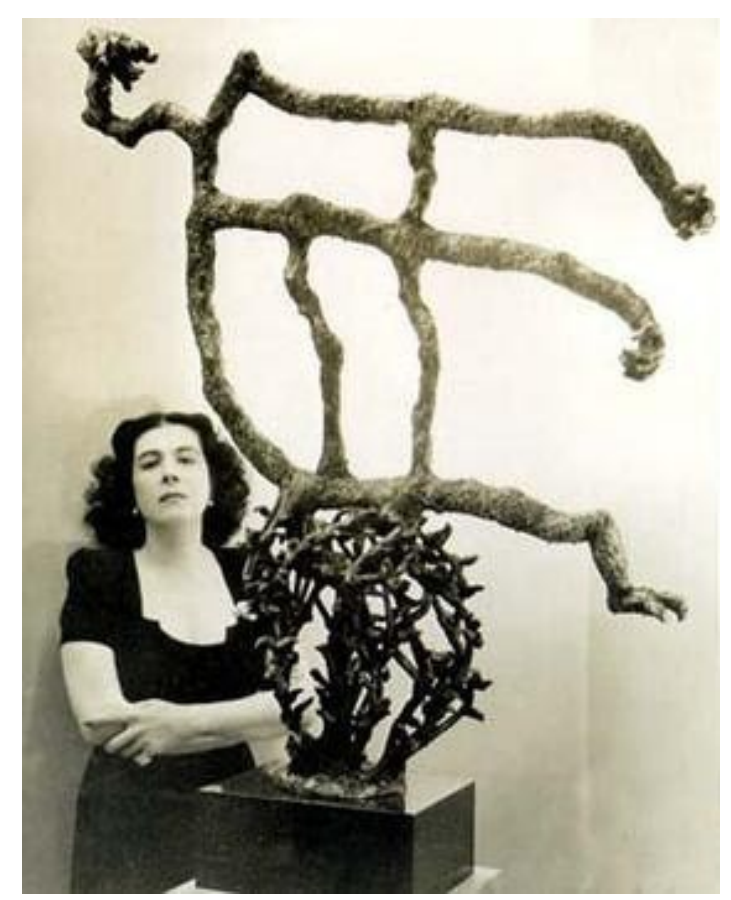

Fig.3. Maria Martins com uma obra sua, em foto da Coleção da Embaixada Brasileira em Washington DC, de 1949. Fonte: https://mam.rio/artistas/maria-martins/

Márcia X e Maria Martins ambas artistas fenomenais, brasileiras do século XX, com trabalhos que apresentam potências distintas, e ao mesmo tempo semelhantes. Martins mais agressiva e abertamente feroz, já Márcia X de forma a realizar uma inteligente provocação. Sendo assim, meu objetivo nesse Previously foi trazer o herege em suas mais diversas possibilidades.

\section{Anteriormente...}

"Se o senhor não tá lembrado Dá licença de conta..."

(Barbosa, 1951)

Eu, Dariane Martiól, entrei na Belas (Escola de Música e Belas Artes do Paraná) no ano de 2017 quando as aulas aconteciam em três prédios, um situado na rua Francisco Torres, outro na Comendador Macedo e o outro na rua Benjamin Constant, todos localizados no centro de Curitiba. Apesar da infraestrutura precária dos três edifícios, nós das Artes Visuais tínhamos uma galeria e um ateliê de pintura. $\mathrm{O}$ tempo de deslocamento entre os prédios era em média 5 minutos (Figura 4). 


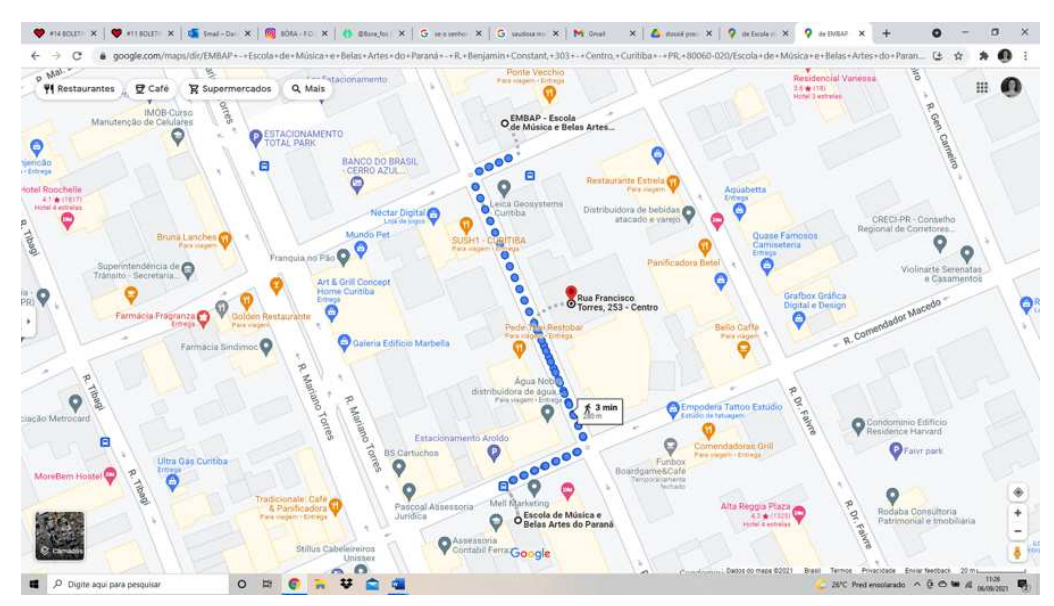

Fig.4. Distância entre os prédios. Fonte: Googlemaps

Foi no ano de 2019 que ganhamos um novo prédio. Na verdade, essa nova sede substituiu o prédio da rua Francisco Torres, onde estavam o ateliê de pintura e a galeria. Uau. Que maravilha! Um prédio sem chão de assoalho, sem madeira rangendo, sem barulhos dos encanamentos sanitários. Não era o prédio pelo qual os/as/es professores lutam há anos, mas estava bom. Ou talvez eu devesse dizer: "estaria bom se eu fosse aluna de música".

Com o novo prédio na rua Barão do Rio Branco ganhamos um bonito auditório, mas perdemos a galeria de arte. Perdemos também as paredes entre as salas de aula. Infelizmente, as treliças que improvisadamente delimitavam os espaços naquele imenso salão bloqueando a visão entre as turmas não isolava o barulho, nem impedia o trânsito de pessoas durante as aulas, o que nos distraía constantemente.

Em poucos meses, alguns banheiros e torneiras pararam de funcionar. Foi um grande transtorno, principalmente para os/as/es estudantes que precisavam de água para limpar seus materiais. Logo o elevador também estragou, alguns/as colegas sofreram pela falta de acessibilidade. Muitas escadas; era difícil subir até o $3^{\circ}$ piso carregando os materiais. O elevador do prédio na sede da Comendador também falhava com frequência. Talvez isso do elevador fosse critério de escolha para prédios, juntamente com banheiro interditado, mau cheiro dos encanamentos e alagamento do ateliê de escultura sempre que houvesse chuva intensa.

Um dos principais problemas que enfrentei naquele ano foi a distância entre os prédios. Tinha que correr de uma aula até a outra e sempre chegava atrasada (Figura 5). 


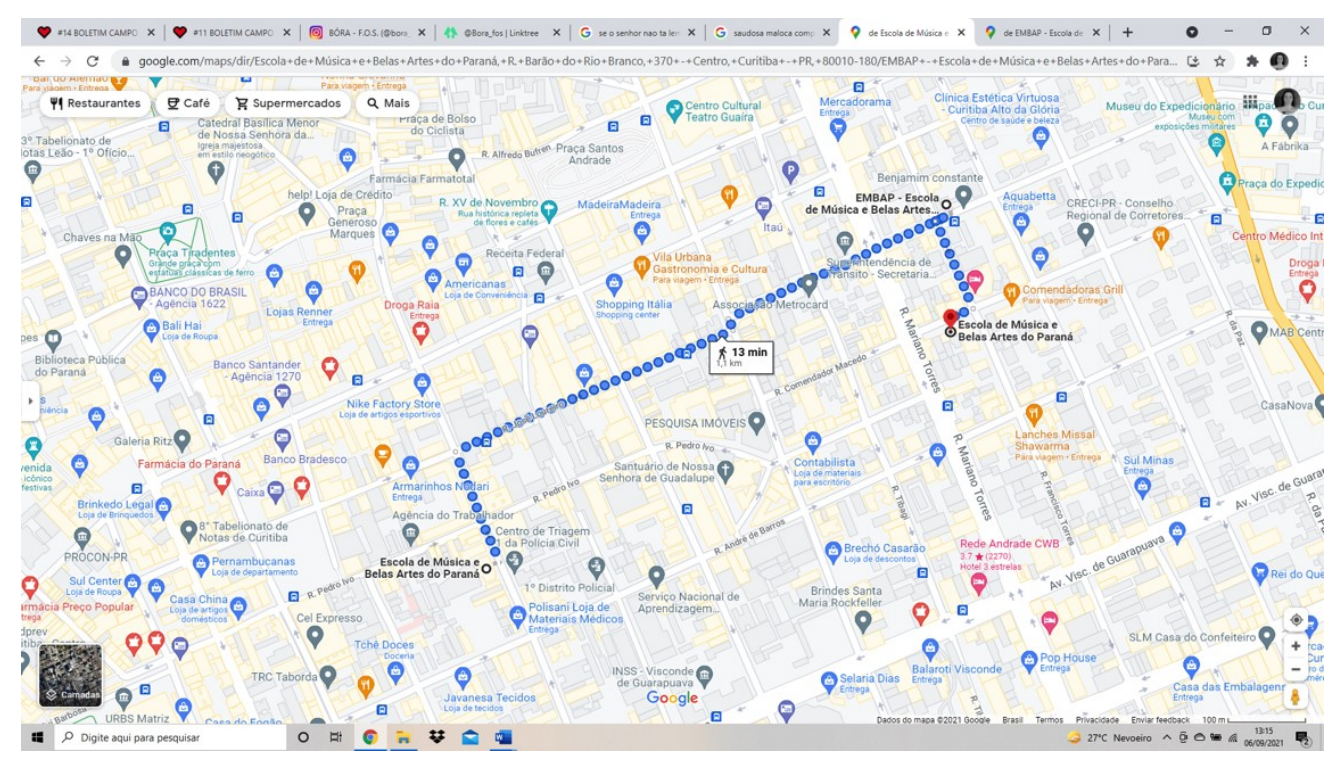

Fig.5. Distância entre os prédios II. Fonte: Googlemaps

Esse preâmbulo é pertinente, porque a minha leitura do Campo Remoto é em comparação com o que experimentei na Belas desde o meu ingresso. Depois de três anos de movimentação e reivindicação por um espaço físico que respeitasse nossos corpos, a pandemia trouxe novas barreiras.

Dadas as circunstâncias, o Campo Remoto foi uma grande e rápida sacada que obviamente não agradou a todos/as/es, mas possibilitou continuar os estudos. O desafio já não era se deslocar de um prédio até o outro, mas o de se colocar diante do computador durante as aulas. Foi uma mudança radical. Contudo, foi muito interessante ver as "janelas" lado a lado e perceber como os/as/es professores se articularam e se empenharam em nos atrair para as atividades.

Essas percepções me instigaram a participar ativamente no Previously. A temporada HH cujo primeiro "H" correspondia à "História" e o segundo variava em cada episódio, teve uma proposta decolonial, o que me estimulou mais ainda por ter relação com os temas que eu estava interessada. No final de cada aula, ficava definido quem seria a pessoa a fazer a abertura na aula seguinte. Me senti especialmente motivada pelo episódio História Hedionda e me prontifiquei para fazer o próximo Previously.

De acordo com a professora Isadora Mattiolli, a partir do hediondo na história da arte e perpassando diferentes contextos culturais, temporais e geográficos, nesse episódio:

O propósito foi o de perceber como o hediondo pode figurar nas artes indo além das representações de situações abomináveis nas mais diversas linguagens. A arte pode estar à serviço do hediondo, pode reivindicar uma posição ética frente ao hediondo, pode torná-lo tema e institucionalizá-lo, como pontuou a professora Katyucia, ao analisar a discussão. (Mattiolli, 2020)

Deste modo, montei a apresentação com base nas ligações que estabeleci entre as exposições dos professores e as minhas referências, buscando propor um diálogo que se desdobrasse em outras narrativas. 
Sobre o conceito de hediondo, ele implica em algo que causa horror, algo repulsivo. No entanto, assim como a beleza, a justiça e o bem, "hediondo" pode ser um juízo de valor subjetivo. Por exemplo, há quem considere um ato hediondo que algum presidente durante uma pandemia promova aglomeração, desrespeitando medidas básicas de prevenção ao contágio do vírus, do mesmo modo como há quem possa apoiar tal feito sem ver nisso motivo para revolta.

Então, busquei por histórias que pressupus terem maior concordância quanto ao caráter hediondo, que houvesse um consenso maior sobre a repulsividade inerente à elas. Sem pretensão de me aprofundar no conteúdo abordado em aula, mas com a intenção de contextualizar os temas tratados, cito a seguir um recorte dos tópicos apresentados pelos professores em História Hedionda:

A professora Katyucia Perigo fez a introdução falando sobre algumas artistas que trabalharam temas relacionados à violência étnica e de gênero, entre elas a brasileira Rosana Paulino (1967), Doris Salcedo (Colômbia, 1958) e Ana Mendieta (Cuba, 1948 - EUA, 1985). Falou também sobre a história de Maria Bueno, que foi brutalmente assassinada por um soldado no centro de Curitiba, em 1893. Em seguida, o professor Fabricio Nunes discorreu sobre os sacrifícios humanos nas culturas pré-colombianas e suas representações em cerâmica, gravuras, esculturas, e arquitetura.

Além de propor reflexão sobre uma estética do encarceramento a partir de fragmentos da exposição "Marking Time Art in the Age of Mass Incarceration", com curadoria de Nicole R. Fleetwood, o professor Luiz Carlos Sereza tratando do assassinato como forma de Belas Artes abordou a HQ "Do inferno" escrita por Alan Moore.

Para finalizar, com o título "Obscenidades, camuflagens e visibilidades difíceis", o professor Ricardo Ayres apontou para a parceria entre a arte e a guerra quando no uso da camuflagem militar inspirada em formas cubistas, bem como no conceito de soft power e o envolvimento da Agência Central de Inteligência Americana com o expressionismo abstrato.

As correlações estabelecidas a partir dessas abordagens me levaram a pensar na Colônia Juliano Moreira, uma instituição psiquiátrica criada com fins higienistas no Rio de Janeiro na primeira metade do século XX, a qual é descrita por Daniela Arbex no livro Holocausto brasileiro. Foi nesse hospital que o artista Arthur Bispo do Rosário permaneceu internado desde 1964 até o dia de sua morte, no ano de 1989.

Também pensei nos inúmeros casos de assassinatos de pessoas trans e travestis. Comentei sobre Laura Vermont que em 2015 foi espancada por um grupo de rapazes e posteriormente agredida e baleada por dois policiais militares. Laura foi brutalmente assassinada em São Paulo aos 18 anos. Em seguida apresentei o trabalho da cantora, compositora, artista visual e ativista da visibilidade LGBTQIA+ Rosa Luz que denuncia a sociedade cisheteronormativa, elitista e racista do mesmo modo como os trabalhos em escultura, performance, joalheria e audiovisual de Lyz Parayzo, artista brasileira que discute questões decoloniais.

Para fazer o link entre as questões de violência de gênero e a fala do professor Fabricio Nunes sobre sacrifício e autossacrifício, aludi à Parada do Orgulho LGBT em 2015, na qual a atriz e modelo Viviany Beleboni teve sua imagem viralizada ao aparecer presa em uma cruz com os dizeres "Basta de homofobia". Associei o rito católico da eucaristia com um canibalismo simbólico, já que a hóstia e o vinho representam o corpo e sangue de Cristo: o cordeiro imolado. Nisso vi relação também com a obra freudiana Totem e Tabu, em que no mito da horda primitiva os filhos devoram o pai, depois de matá-lo.

Por fim, a história do Jack Estripador me remeteu a outro serial killer. Edward Theodore Gein ao confessar o assassinato de duas mulheres foi internado em uma instituição psiquiátrica, em 1968 nos Estados Unidos. Ele também exumava lápides e fazia objetos com ossos e peles humanas. Essa história inspirou não só Alfred Hitchcook no filme Psicose, como também uma coleção de roupas 
da marca Kayla Arenafx, cujas peças em látex simulam a pele humana com pedaços de orelhas, olhos, entre outras partes. Nessa pegada um tanto bizarra, mas com uma boa dose de crítica social, a artista argentina Nicola Constantino criou uma boutique onde todas as peças vendidas eram recobertas por um material que imitava a pele e mamilos femininos. A "Peletería Humana" jogava com a questão do desejo de consumo através de dois itens fundamentais: a roupa e o sexo.

Entendo que a narrativa apresentada por mim apontou para alguns modos de como figuras desviantes das normas hegemônicas foram e são caladas, seja por meio de intervenções psiquiátricas, da opressão, da violência ou da morte. Apontou também para como a arte lida com essas questões e como artistas podem através da arte deixar seu testemunho de vida e resistência.

Falando em resistência, aproveito esse espaço para agradecer a todas os/es professoras/es que se dedicaram e apoiaram essa experiência, que foi nova tanto para os/as discentes quanto para os/as docentes. É incrível pensar também que as pessoas que mais se dedicaram e se esforçaram para que as aulas acontecessem da melhor maneira possível, dentro dos limites impostos pela situação pandêmica, foram as mesmas que eram encontradas nas manifestações, nos debates e reuniões, engajadas na luta por um espaço melhor.

Pode ser fácil gostar de professores/as descolados/as/es, engraçados/as/es e queridinhos/as/es, mas definitivamente precisamos de professores/as comprometidos/as com a educação. Professores/as ousados, que não se preocupam em nos agradar o tempo todo, que por vezes parecem demasiadamente sérios, mas que sempre estão na linha de frente. Professores/as que mais do que se adaptar a novas modalidades de ensino, criam novas possibilidades, recriam ambientes e se importam com a qualidade e bem estar de todos/as/es.

Se durante o Campo Remoto tive a oportunidade de apresentar o "anteriormente", aqui aproveitei a oportunidade para falar de um outro anteriormente: aquele de reivindicação por uma infraestrutura segura, adequada, com garantias de boas condições para o ensino e aprendizado. É um "anteriormente" muito presente, que se fará mais presente ainda no futuro em breve. Que estejamos preparadas/des/dos para quando nos reencontrarmos fisicamente, que possamos além de nos abraçar, darmos as mãos para seguir a luta por nossos direitos.

"Saudosa maloca, maloca querida Dim dim donde nós passemo os dias feliz de nossa vida..."

(Barbosa, 1951)

\section{Considerações finais}

A maneira que encontramos para podermos seguir com nossas atividades durante a pandemia ainda nos faz pensar sobre o processo de ensino-aprendizagem disparado naquele período que realizamos o Campo Remoto.

$\mathrm{Na}$ data de centenário de Paulo Freire, um dos mais importantes pedagogos brasileiros, seus ensinamentos são ainda importantes para pensarmos a participação no contexto educacional brasileiro, e cada vez mais neste momento de subsequentes ataques à democracia e à educação. Para o autor, a natureza humana é inconclusa: "É na inconclusão do ser, que se sabe como tal, que se funda a educação como processo permanente." (FREIRE, 1996, p. 58). Quando nos abrimos ao diálogo, à escuta, nos percebemos buscando aprender, um saber fundante da prática educativa e de uma convivência mais respeitosa. 
A participação dos/as estudantes no Previously, Newsletter e outras ações do Campo Remoto deflagrou também o que o autor diz sobre o embaralhamento das relações de educador/a/e e educando/a/e: "Já agora ninguém educa ninguém, como tampouco ninguém se educa a si mesmo: os homens se educam em comunhão, mediatizados pelo mundo." (FREIRE, 2015, p. 96). E esse texto, mais uma vez, se volta para pensar sobre a experiência de ensino-aprendizado e nos colocarmos dispostas/os/es a esse processo contínuo de trocas.

\section{Referências:}

BARBOSA, Adoniran. Saudosa Maloca. Disponível em: https://www.letras.mus.br/adoniranbarbosa/43969/. Acesso em 22 setembro 2021.

FREIRE, Paulo. Pedagogia da autonomia: saberes necessários à prática educativa. 40a reimpressão. São Paulo: Terra e Paz, 1996.

FREIRE, Paulo. Pedagogia do oprimido. 59`a edição. São Paulo: Terra e Paz, 2015.

GALVÃO, Carlos Fernando. Pandemia e pobreza: a sindemia exposta da crueldade humana. Edição Novembro 2020. São Paulo: Le Monde Diplomatique Brasil, 2020, disponível em $<$ https://diplomatique.org.br/pandemia-e-pobreza-a-sindemia-exposta-da-crueldade-humana/ $>$. Acesso em: 30 ago 2021.

BAUSBAUM, Ricardo. "X" Percursos de alguém além de equações. In: CONCINNITAS: Rio de Janeiro, v.1, n. 4., p. 174 - 197, 2003. Disponível em: https://www.epublicacoes.uerj.br/index.php/concinnitas/article/view/42762/29524. Acesso em: 14 set. 2021.

MATTIOLLI, Isadora. (2020 Outubro). Sinopse HH \# História Hedionda. Boletim do Campo Remoto. Disponível em: < $\underline{\text { https://tinyletter.com/campusremotus/letters/11-boletim-campo-remoto }>}$ 